Discussion Paper No. 06-093

\title{
R\&D Incentives, Compatibility and Network Externalities
}

Daniel Cerquera

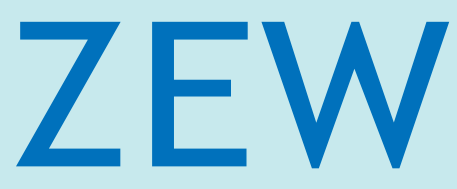

Zentrum für Europäische Wirtschaftsforschung $\mathrm{GmbH}$

Centre for European

Economic Research 
Discussion Paper No. 06-093

\title{
R\&D Incentives, Compatibility and Network Externalities
}

\author{
Daniel Cerquera
}

Download this ZEW Discussion Paper from our ftp server:

ftp://ftp.zew.de/pub/zew-docs/dp/dp06093.pdf

Die Discussion Papers dienen einer möglichst schnellen Verbreitung von neueren Forschungsarbeiten des ZEW. Die Beiträge liegen in alleiniger Verantwortung der Autoren und stellen nicht notwendigerweise die Meinung des ZEW dar.

Discussion Papers are intended to make results of ZEW research promptly available to other economists in order to encourage discussion and suggestions for revisions. The authors are solely responsible for the contents which do not necessarily represent the opinion of the ZEW. 


\section{Non-technical summary}

An industry exhibits network externalities when the benefit that consumers enjoy from purchasing one or several of its goods depends on the number of other consumers that use the same and/or compatible products. For the firms in those sectors (e.g. telecommunications, consumer electronics, operating systems, etc.), the presence of network externalities implies that the attractiveness of their products is a function of their quality-adjusted prices and the potential benefit attached to their expected network sizes.

Several studies have shown how pricing considerations, as well as compatibility, entry and investment decisions are affected by the presence of network externalities. Moreover, due to the presence of these externalities, firms in network industries might even follow very different rules from those observed in traditional industries. While the producer of a new product in a conventional industry tends to place it on the market early, to differentiate the good as much as possible, to protect it from imitation and to charge high prices, successful producers of network goods have often done the opposite.

This paper analyzes how network externalities influence industry Research and Development $(\mathrm{R} \& \mathrm{D})$ incentives when two network technologies compete. The paper focuses on the levels of $R \& D$ investments, the social efficiency of those efforts and the role of networks' compatibility.

The paper presents four main results. First, for low cost of innovation entry does not occur at all and for high cost of innovation, entry occurs with positive probability. Low cost of innovation implies that through investments the incumbent firm is able to preempt the entrant. Second, when entry is possible, the incumbent invests always more than the entrant and, therefore, there is a high probability that the incumbent maintains its monopoly position. This result implies that, even though the incumbent has an advantage to keep monopolizing the market, he is forced to innovate given the threat of entry. Third, from a welfare perspective, the incumbent invests too little and the entrant invests too much given the existence of locked-in consumers. These results are solely due to the presence of network externalities. Fourth, by choosing to produce compatible products, firms do not necessarily reduce the R\&D competition intensity as has been suggested in the literature. 


\title{
R\&D Incentives, Compatibility and Network Externalities
}

\author{
Daniel CERQUERA*
}

December 27, 2006

\begin{abstract}
This paper analyzes the impact of network externalities on R\&D competition between an incumbent and a potential entrant. The analysis shows that the incumbent always invests more than the entrant in the development of higher quality network goods. However, the incumbent exhibits a too low level of investments, while the entrant invests too much in $R \& D$ in comparison with the social optimum. In the model entry occurs too often in equilibrium. These inefficiencies are solely due to the presence of network externalities. By choosing compatible network goods, firms do not necessarily reduce the $\mathrm{R} \& \mathrm{D}$ competition intensity.
\end{abstract}

Keywords: Network externalities, Innovation, Imperfect Competition.

JEL Classification: D21, D85, L13, O31.

\footnotetext{
*cerquera@zew.de. Centre for European Economic Research (ZEW), Mannheim, Germany. Research Group Information and Communication Technologies. I would like to thank Irene Bertschek, Toker Doganoglu, Stefan Mittnik, Monika Schnitzer, Sven Rady and an anonymous referee for very useful comments. Most of this research was completed at the Center for Information and Network Economics at the University of Munich. Generous financial support from Volkswagen Stiftung and the Munich Graduate School of Economics made this research possible. All errors are mine.
} 


\section{Introduction}

An industry exhibits network externalities when the benefit that consumers enjoy from purchasing one or several of its goods depends on the number of other consumers that use the same and/or compatible products. For the firms in those sectors (e.g. telecommunications, consumer electronics, operating systems, etc.), the presence of network externalities implies that the attractiveness of their products is a function of their quality-adjusted prices and the potential benefit attached to their expected network sizes (i.e. installed bases).$^{1}$

Several studies have shown how pricing considerations, as well as compatibility, entry and investment decisions are affected by the presence of network externalities.2. Moreover, due to the presence of these externalities, firms in network industries might even follow very different rules from those observed in traditional industries $3^{3}$

This paper analyzes how network externalities influence industry Research and Development $(\mathrm{R} \& \mathrm{D})$ incentives when two network technologies compete. The paper focuses on the levels of $R \& D$ investments, the social efficiency of those efforts and the role of networks' compatibility.

Rapid technological progress derived from $\mathrm{R} \& \mathrm{D}$ competition is a common observation in many industries with network externalities. Technological innovations allow rivalling firms to introduce new products like interactive TV, Digital Versatile Disk (DVD), and digital imaging. In nascent industries, extensive investments in $R \& D$ are usually required to introduce new standards or dominant designs.

However, the literature on R\&D and technology choice in industries that exhibit network externalities is still in its early stage of development. The existing literature, in its great majority, takes the process of $\mathrm{R} \& \mathrm{D}$ as exogenously given and analyzes the conditions under which a new innovation is adopted (Farrell and Saloner (1985, 1986), Katz

\footnotetext{
${ }^{1}$ Katz and Shapiro $(1985,1986)$ and Farrell and Saloner $(1985,1986)$ present the seminal treatments, and Katz and Shapiro (1994) and Economides (1996) present excellent surveys on network markets.

${ }^{2}$ See, for example, Gabel (1991), Besen and Farrell (1994), Katz and Shapiro (1994), Grindley (1995) and Shapiro and Varian (1999) for general analyses of the impact of network externalities on firms' strategies.

${ }^{3}$ While the producer of a new product in a conventional industry tends to place it on the market early, to differentiate the good as much as possible, to protect it from imitation and to charge high prices, successful producers of network goods have often done the exact opposite. See Grindley (1995).
} 
and Shapiro (1986, 1992), De Bijil and Goyal (1995), Shy (1996), Fudenberg and Tirole (2000), among others). Moreover, most of the work devoted to the analysis of adoption of new technologies with network externalities considers situations where the entrant arrives with a (exogenously given) new technology, without considering a strategic response by the incumbent to the threat of entry.

This paper proposes a simplified two-period duopoly model of competition with uncertain technological progress, in order to determine the private incentives to invest in R\&D. The model is simple enough to be able to isolate the main forces behind the incentives to innovate and the role of network externalities. Specifically, we consider an incumbent firm with an installed base and a potential entrant that challenges the incumbent only once. We assume a uncertain technological progress. In particular, by investing in R\&D before price competition takes place, each firm can influence the probability of developing a better technology to compete with.

We also consider the social incentives to innovate and compare the results with the market outcome. We show the conditions under which potential inefficiencies arise and propose, with our model, an explanation to these inefficiencies. Finally, we consider the role of compatibility choice and its impact on the R\&D incentives.

We present four main results. First, for low cost of innovation entry does not occur at all and for high cost of innovation, entry occurs with positive probability. Low cost of innovation implies that through investments the incumbent firm is able to preempt the entrant. Second, when entry is possible, the incumbent invests always more that the entrant and, therefore, there is a high probability that the incumbent maintains its monopoly position. This result implies that, even though the incumbent has an advantage to keep monopolizing the market, he is forced to innovate given the threat of entry. Third, from a welfare perspective, the incumbent invests too little and the entrant invests too much given the existence of locked-in consumers. These results are solely due to the presence of network externalities and are in contrast with the results reported in Kristiansen (1996). Fourth, by choosing to produce compatible products, firms do not necessarily reduce the $R \& D$ competition intensity as has been suggested for example in Katz and Ordover (1990) and Kristiansen (1998). Moreover, for high cost of innovation

\footnotetext{
${ }^{4}$ Some exceptions that will be discussed below include Kristiansen $(1996,1998)$.
} 
compatibility may even increase the pace of innovation observed in the industry.

Even though our model is related to the literature on network externalities, the modeling strategy, as well as some results, differ with existing analyses. For instance, Kristiansen (1996) also analyzes endogenous and uncertain technological process in a network industry. He presents a model to describe how firms, an incumbent and a potential entrant, choose among different R\&D projects to develop a new incompatible technology. In particular, he discusses the firms' choices of R\&D projects in terms of the risk associated to each of them. To isolate the role of the riskiness of such projects, Kristiansen (1996) assumes a mean-preserving spread criterion in the R\&D technology. That is, even though riskier projects exhibit higher returns and lower probability of success, the expected value of all R\&D projects is the same.

Particularly, he finds that from a social welfare point of view, the incumbent chooses a too risky and the entrant a too certain R\&D project. This inefficiency arises because of the existence of an installed base of locked-in consumers of the incumbent's technology that is not taken into account when the firms decide on the $R \& D$ projects. The entrant chooses a too low risk project because it exhibits a high probability of success (i.e. entry) but, if successful, his $R \& D$ project provides a too low value for the society. The incumbent chooses a too risky project because, if successful, it can extract high consumer surplus. However, his choice does not internalize the potential welfare loss of the locked-in consumers in the case of successful entry by a firm with an incompatible technology.

As in Dasgupta and Maskin (1987), Kristiansen (1996) adopts the additional assumption that riskier R\&D projects entail unambiguously higher costs of development. Although plausible, this assumption implies for his results that the incumbent firm invests too much and the entrant firm too little in comparison with the social optimum. We believe that in network industries the opposite phenomenon is commonly observed. Namely, entrants usually tend to heavily (over) invest in R\&D in order to introduce new network incompatible technologies (e.g. interactive TV, Compact Disk (CD), Digital Versatile Disk (DVD), and digital imaging). We propose a model where this is the case. In addition, Kristiansen (1996) shows, as in our model, that the differences between private and socially optimal $R \& D$ initiatives are due to the presence of network externalities.

In a similar paper, Choi (1994) studies an entrant's choice among R\&D projects with 
different risks in a two period model in which consumer can delay adoption. As in Kristiansen (1996), Choi (1994) also considers the case of mean-preserving spread criterion in the R\&D technology. In his model, the quality of the incumbent technology is constant over the two periods, while the entrant's technology evolves stochastically. By choosing a level of risk, the entrant firm may affect the distribution of the quality of its good to be introduced in the second period. Two buyers enter sequentially in each period. The first buyer can observe the R\&D project (i.e. risk choice) of the potential entrant and may decide to wait until the second period to make a purchase. Choi (1994) concludes that the first buyer may adopt a technology too early in relation with the social optimum. In addition, similar to Kristiansen (1996), the paper shows that the potential entrant chooses a low level of risk in comparison with the level that maximizes social welfare. However, Choi (1994) does not consider the costs associated with the selection of the R\&D projects, which are an important dimension of the incentives to innovate. We also depart from his work by considering the strategic role of the R\&D decision by the incumbent firm.

In a more recent work, Kristiansen (1998) studies the decisions of entry and compatibility in a duopoly market in the presence of network externalities. R\&D incentives are endogenous in the sense that an earlier entry decision imply higher costs. However, this extra cost does not affect the probability distribution of the quality of the network goods and represents more closely a sunk entry cost rather than a uncertain R\&D investment. Kristiansen (1998) shows that when the firms choose to produce compatible goods, it is optimal for them to introduce their goods later, and therefore compatibility reduces the $\mathrm{R} \& \mathrm{D}$ competition intensity observed by the two firms. We present the opposite result in a model where investments in $R \& D$ do affect the probability distribution of the quality of the network goods.

The paper is organized as follows. In section 2 we present the model. In section 3 we analyze the market equilibrium that determines the private incentives to innovate. In section 4 we present the socially optimal outcome and compare it with the results of section 3 . Section 4 considers the role of compatibility. Section 5 concludes. 


\section{The Model}

Consider a two-period model of an industry that exhibits network externalities. In period 1 there is an incumbent monopolist, $I$, that produces a network good associated with a quality level $q_{1}$. The incumbent monopolist serves the entire market in this period and builds an installed base. Between periods 1 and 2, the incumbent can invest in a potential innovation, which will enable him to achieve, with probability $s_{I}$, a higher quality level $q_{2}$ for the good he produces in period 2. We denote this quality improvement as $q_{2}-q_{1}=q_{\Delta}>0$. For the cases when the innovation is not achieved, event that occurs with probability $1-s_{I}$, the incumbent produces in period 2 the same good it produced in period 1. The cost of this investment increases with the probability of achieving the innovation and is assumed to be quadratic and given by $k s_{I}^{2} / 2$, where $k$ is a cost parameter.

Furthermore, we introduce a potential entrant, $E$, who can also invest in innovation and enter the market with a network good in period 2. As the incumbent, the cost of the investment for the entrant is given by $k s_{E}^{2} / 2$, where $s_{E}$ is the probability that the entrant develops the innovation and enters the market with a good of quality $q_{2}$. It is assumed that in the case that the entrant does not achieve the innovation, event that occurs with probability $1-s_{E}$, it is able to "copy" the technology used by the incumbent in period 1. For simplicity, it is assumed that the problem of both firms reduces to choose the probability $s_{I}$ and $s_{E}$ that the innovation is achieved in period 2 .

On the demand side, it is assumed that each period a group of homogeneous consumer of size 1 arrives in the market. Given consumer homogeneity, we can assume without loss of generality that in each period only one consumer arrives in the market. In the model, each consumer exhibit an inelastic demand for a single unit of a network good and purchases as soon as he arrives in the market. There is no discounting. In particular, the per-period utility that a consumer derives from a network good is given by $q+b x$ where $q$ is the quality of the good (i.e. stand-alone value), and $b$ is the extent of the network benefit attached to the good given that the number of consumers buying the same good is $x$.

The timing of the model is as follows. At the beginning of period 1, the incumbent produces a network good with quality $q_{1}$, sets a price and the first consumer buys. Between 
periods 1 and 2, the incumbent invests in order to improve its good. At the same time, a potential entrant invests in order to enter the market with an improved good. At the beginning of period 2, the outcome of the innovation is realized, price competition takes place, the new consumer arrives in the market and decides on its preferred good.

\section{Market Equilibrium}

In order to characterize the subgame-perfect equilibria in this game we proceed backwards. We start with the pricing and consumption decision in period 2.

\subsection{Second Period Sales}

In the second period firms decide on the price they charge, and the second consumer decides on the good he prefers. However, these two decisions are affected by first period purchases and the outcome of the innovation process. Recall that in period 1 the incumbent firm monopolizes the market and is able to serve it completely. The evolution of the first period is assumed exogenous. Therefore, an installed base of size 1 is built and carried into the second period. Regarding the innovation process, we distinguish among four cases; $B$ denotes the case in which both firms innovate; $I$ and $E$ denote the cases in which only the incumbent or only the entrant innovates, respectively; and $N$ denotes the history in which no firm innovates. We define four subgames $\Gamma^{B}, \Gamma^{I}, \Gamma^{E}$ and $\Gamma^{N}$ for each case, respectively.

In subgame $\Gamma^{B}$, both firm innovate and therefore are able to enter the market with a good of quality $q_{2}$. However, given the existence of an installed base, firms compete in a quality differentiated duopoly. It is further assumed that consumers are able to coordinate on the Pareto-optimal equilibrium. Therefore, they compare the maximum surplus that can be obtained from each technology and decide accordingly $5^{5}$ Thus, the benefit gross of price provided by the incumbent is equal to $q_{2}+2 b$, and equal to $q_{2}+b$ for the entrant. Bertrand competition implies that the incumbent's price is equal to $p_{I}=b$ and sells to the second consumer, while the entrant's price equals $p_{E}=0$ and does not enter the market.

\footnotetext{
${ }^{5}$ See Katz and Shapiro (1986) and Farrell and Katz (2005).
} 
In subgame $\Gamma^{I}$, the incumbent firm innovates and sells a good of quality $q_{2}$ offering a gross benefit of $q_{2}+2 b$, while the entrant provides a surplus of $q_{1}+b$. Again, Bertrand competition implies an incumbent's price of $p_{I}=q_{\Delta}+b$ and sells to the second consumer, while the entrant's price equals $p_{E}=0$ and does not enter the market.

In subgame $\Gamma^{E}$, the entrant firm is the only innovator and sells a good of quality $q_{2}$ offering a gross benefit of $q_{2}+b$, while the incumbent provides a surplus of $q_{1}+2 b$. In this subgame, entry takes place whenever $q_{\Delta}>b$. In that case, Bertrand competition implies an entrant's price of $p_{E}=q_{\Delta}-b$ and sells to the second consumer, while the incumbent's price equals $p_{I}=0$.

In subgame $\Gamma^{N}$, no firm innovates and both offer a good of quality $q_{1}$. However, the incumbent exhibits an installed base advantage and provides a surplus equal to $q_{1}+2 b$, compared to $q_{1}+b$ from the entrant. Bertrand competition implies that the incumbent's price is equal to $p_{I}=b$ and sells to the second consumer, while the entrant's price equals $p_{E}=0$ and does not enter the market.

Assumption 1. The value of the innovation is greater than the value of the installed base. $q_{\Delta}>b$.

This assumption gives the opportunity to the entrant to enter the market. That is, the value of the innovation should be able to more than compensate the network benefits provided by the incumbent firm and drives the result presented for subgame $\Gamma^{E}$.

We can summarize the outcome of second period price competition in the following proposition.

Proposition 1. Given assumption 1, each second period subgame-perfect price equilibrium is unique. No entry takes place in subgames $\Gamma^{B}, \Gamma^{I}, \Gamma^{N}$, while the entrant overtakes the market in subgame $\Gamma^{E}$. Equilibrium prices are given as follows:

i. In subgames $\Gamma^{B}$ and $\Gamma^{N}, p_{I}=b$ and $p_{E}=0$.

ii. In subgame $\Gamma^{I}, p_{I}=b+q_{\Delta}$ and $p_{E}=0$.

iii. In subgame $\Gamma^{E}, p_{I}=0$ and $p_{E}=q_{\Delta}-b$. 
Proposition 1 implies that entry only occur when subgame $\Gamma^{E}$ is realized. That is, the only opportunity for the entrant to enter the market is when it achieves the innovation and the incumbent does not.

\subsection{First Period Investment Decisions}

Given the above analysis of the period 2 play, we now solve for the subgame-perfect equilibrium of the entire game considering the optimal investment behavior of both firms.

The profit function of the incumbent is therefore given by,

$$
\max _{s_{I}} s_{I} s_{E} b+s_{I}\left(1-s_{E}\right)\left(b+q_{\Delta}\right)+\left(1-s_{I}\right)\left(1-s_{E}\right) b-k s_{I}^{2} / 2,
$$

where $k$ is a cost parameter.

Analogously, and following the analysis of the period 2 price competition, the profit function of the entrant is therefore given by,

$$
\max _{s_{E}}\left(1-s_{I}\right) s_{E}\left(q_{\Delta}-b\right)-k s_{E}^{2} / 2
$$

The first-order conditions for an interior solution are given by,

$$
q_{\Delta}-s_{E}\left(q_{\Delta}-b\right)-k s_{I}^{*}=0
$$

for the incumbent firm, and,

$$
\left(1-s_{I}\right)\left(q_{\Delta}-b\right)-k s_{E}^{*}=0
$$

for the entrant firm. Note that whenever the probabilities $s_{I}$ and $s_{E}$ are in the interval $(0,1)$, the second-order conditions are always less than zero and the investment strategies exhibit strategic substitutability. Therefore, we can find the optimal equilibrium levels by solving simultaneously equations (3) and (4) for the values of $s_{I}$ and $s_{E}$. That is, the optimal investment levels are given by,

$$
s_{I}^{*}=1-\frac{k\left(q_{\Delta}-k\right)}{\left(q_{\Delta}+k-b\right)\left(q_{\Delta}-k-b\right)}
$$




$$
s_{E}^{*}=\frac{\left(q_{\Delta}-b\right)\left(q_{\Delta}-k\right)}{\left(q_{\Delta}+k-b\right)\left(q_{\Delta}-k-b\right)}
$$

We can show the following results.

\section{Proposition 2. Given assumption 1.}

i. For $k>q_{\Delta}$ there are unique values of $s_{I}^{*}$ and $s_{E}^{*}$ such that $0<s_{I}^{*}<1$ and $0<s_{E}^{*}<1$. $s_{I}^{*}>s_{E}^{*}$ always holds.

ii. For $k \leq q_{\Delta}$ the equilibrium levels of investment are unique and equal to $s_{I}^{*}=1$ and $s_{E}^{*}=0$.

Proof. Numeral [i.] follows from equations (5) and (6). Numeral [ii.] requires to check the first-order conditions (i.e. equations (3) and (4) ) and it can be seen that $k \leq q_{\Delta}$ implies a corner solution.

Numeral [i.] of proposition 2 implies that entry occurs with positive probability (i.e $\left.\left(1-s_{I}^{*}\right) s_{E}^{*}\right)$ when the cost of innovating, $k$, is relatively high. The intuition for this result is that for moderate costs of innovation, the incentives for the incumbent to innovate are high and therefore achieves the innovation with a high probability. Given that the entrant can only enter the market when the incumbent does not innovate, the entrant has lower incentives to innovate. As the cost of the innovation increases, the incumbent reduces his incentives to innovate and, hence, it is, in expectations, profitable for the entrant to keep investing. However, the installed base advantage of the incumbent limits the incentives to innovate for the entrant.

Numeral [ii.] of proposition 2 states that when the cost of innovation is too low no entry occurs. That is, the incumbent invests its maximum possible amount $s_{I}^{*}=1$ and the entrant has no incentives to innovate and exhibit an investment level equal to $s_{E}^{*}=0$.

These result of proposition 2 can be seen graphically. Figure 1 shows the equilibrium values $s_{I}^{*}$ and $s_{E}^{*}$. For simplicity, this figure considers the case when $b=1$ and $q_{\Delta}=3$ but extends to any parameter configuration, such that the assumptions of the model hold.

Note in the graph the case when the cost of investment are zero or close to zero (i.e. no entry equilibrium due to $k \leq q_{\Delta}$ ). In that situation, the incentives to invest for the incumbent are at its maximum $\left(s_{I}=1\right)$ because investing that amount implies the 


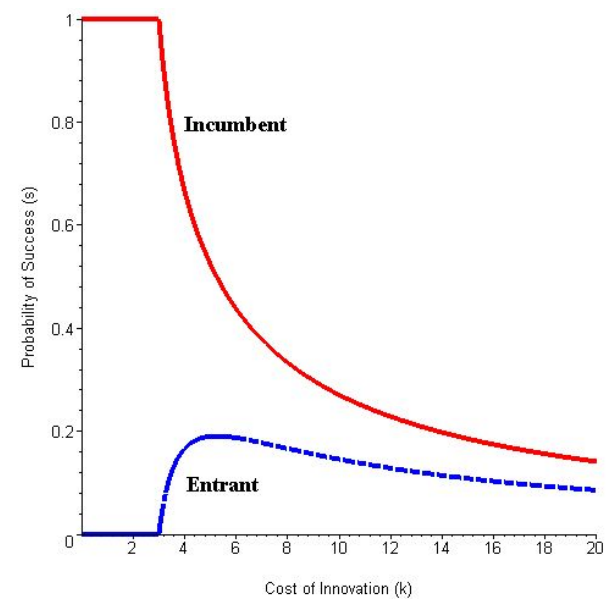

Figure 1: Market Outcome - Investment Levels

achievement of an innovation in the next period at a low cost, and therefore, securing its incumbent position. Conversely, the incentives to invest for the entrant are zero, even though investment is low or even costless. The reason is, no matter how much the entrant invests (even $s_{E}=1$ ), the entrant is never going to takeover the market. Therefore, for costless investment the incumbent firm invests the maximum possible and the entrant firm performs no investment.

However, when the cost of investment starts increasing, it is extremely costly for the incumbent to carry out exactly the maximum possible investment. Therefore, it reduces slightly its level of investment, reducing at the same time its probability of success. As a consequence, now that the incumbent is not achieving the innovation with certainty, there is a room for the entrant to invest and, possibly, takeover the market. For low cost of investment and given that the entrant starts with no investment, the increasing possibility of overtaking the market, when the cost of investment increases, implies that the entrant also increases its investment level in order to take advantage of such opportunity. Nevertheless, as the cost of the innovation increases, the entrant cannot increase its investment level indefinitely because at some point investment efforts become too expensive. After that point, the investment level of the entrant firm must decrease on the cost of such investments. Note that it is always the case that $s_{I}^{*}>s_{E}^{*}$.

This divergence in the investment levels of the two firms only arises because of the 
installed base that the incumbent built in period 1. Therefore, the extent of the network benefit is critical to this result and explains the asymmetric investment levels observed in equilibrium. This is stated in the following proposition.

Proposition 3. Under assumption 1 assume that the network externalities increase (i.e. $b$ increases). In equilibrium,

i. The incumbent invests more in R\&D.

ii. The entrant invests less in R\&D.

Proof. Consider the derivative of equations (5) and (6) with respect to the network externalities parameter.

This proposition says that the presence of network externalities increases the incentives to innovate for the firm that exhibits the installed base. That is, the presence of locked-in consumers implies that successful improvements in the good offered can be profitable. On the other hand, the presence of installed bases reduces the incentives for the entrant firm due to the strategic substitutability with respect to the incumbent's investment level. This result is in contrast with those reported by Kristiansen (1996) in his proposition 2, where higher network benefits imply lower (higher) incumbent's (entrant's) incentives to innovate. One reason for this discrepancy, is due to the fact that the focus of his paper is on the riskiness associated to the R\&D projects undertaken by the firms, and therefore, it implies a different modeling strategy as explained in the introduction.

The previous results can be seen in Figure 2. This figure shows that for $b=0$ both firms exhibit the same incentives to innovate and the size of the difference depends on the extent of the network externalities. It can be shown that the level of $\mathrm{R} \& \mathrm{D}$ when $b=0$ is symmetric and equal to $q_{\Delta} /\left(q_{\Delta}+k\right)$. As $b$ increases, the incentives to innovate behave according to proposition 3 .

In addition, the incentives to innovate are also affected by the size of the expected innovation. This result is presented in the following proposition.

Proposition 4. Assume that the value of the potential innovation increases (i.e. $q_{\Delta}$ increases). In equilibrium,

i. The incumbent invests more in RED. 




Figure 2: Investment Levels and Network Externalities

ii. For low innovation costs the entrant invests less in RED and the opposite occurs for moderate and high innovation costs.

Proof. Consider the derivative of equations (5) and (6) with respect to $q_{\Delta}$.

Figure 3 shows that for moderate and high cost of the innovation, a higher size of the innovation tends to increase the incentives to innovate for both firms. This follows from the higher expected returns that can be made in the future if the installed base is increased (or captured) in period 2. This result is in line with the literature on the incentives to innovate, namely, a higher expected value of being the innovator increases the willingness to pay for the innovation. ${ }^{6}$ In contrast, for low cost of innovation, a higher size of the innovation may reduce the incentives to innovate of the entrant firm. The intuition of this result is similar to the one presented for proposition 2 . That is, when the cost of innovating is low, an increase in the size of the innovation increases the innovation incentives for the incumbent firm. This could lead the incumbent firm to carry out an investment level that is close to the maximum possible, hence, reducing the expected value of the innovation for the entrant and, in consequence, its innovation incentives.

One important question corresponds to the efficiency of the previous results. This analysis is taken into account in the next section.

\footnotetext{
${ }^{6}$ See Reinganum (1989).
} 


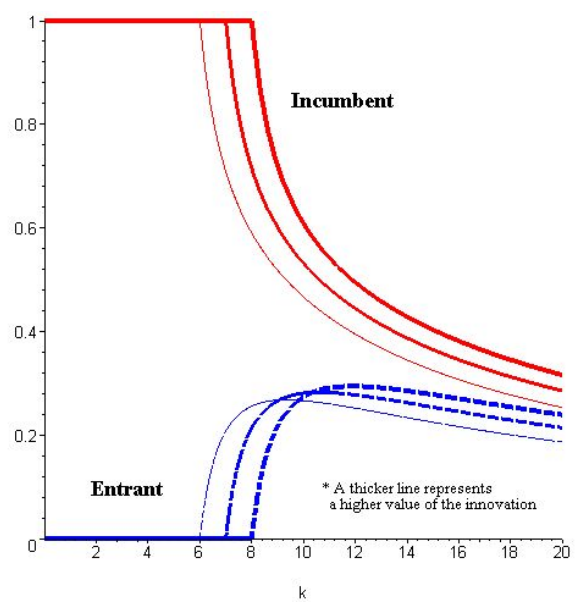

Figure 3: Investment Levels and Size of Innovation

\section{Social Optimum}

In order to analyze the efficiency of the market outcome presented above, this section analyzes the socially optimal outcome. We try to find out what are the differences in the privately determined investment behavior for the incumbent and the entrant firm and what is the role of network externalities in the potential inefficiencies. We first assume that in the second period adoption can be induced by a central planner. Thus, given the outcome of the innovation process, we are able to determine the network good that provides the higher surplus from a social perspective. Next, once we know which network good is going to be induced, we analyze the social incentives to undertake innovative initiatives. We consider the case where the following assumption holds.

Assumption 2. The value of the innovation is greater than the value of the installed base of the old and new consumers. $q_{\Delta}>2 b$.

This assumption is required to consider situations where it is socially optimal to introduce a new technology that is incompatible with the existing installed base.

\subsection{Second Period Technology Adoption}

We consider the maximum surplus that consumers can achieved in the second period given the four possible subgames (i.e. $\Gamma^{B}, \Gamma^{I}, \Gamma^{E}$ and $\Gamma^{N}$ ). We take into account the surplus 
of the first consumer that is locked-in with the incumbent's good, and the surplus of the consumer that arrives in the second period.

In subgame $\Gamma^{B}$, the social surplus provided by the incumbent's good is equal to $q_{1}+2 b$ and $q_{2}+2 b$ for the first and second period consumer, respectively. This provides a total social surplus of $q_{2}+q_{1}+4 b$ in the second period if the network good of the incumbent firm is adopted. Analogously, the entrant's good provides a surplus equal to $q_{1}+b$ and $q_{2}+b$ for the first and second period consumer, respectively. The total social surplus from the entrant's good is $q_{2}+q_{1}+2 b$. Clearly, due to the role of the installed base, the incumbent's good provides a higher overall social surplus and therefore is adopted in the case subgame $\Gamma^{B}$ is realized.

Following a similar analysis, we can show that in subgames $\Gamma^{I}$ and $\Gamma^{N}$ the incumbent's technology is induced with total surplus equal to $q_{2}+q_{1}+4 b$ and $2 q_{1}+4 b$, respectively.

Given assumption 2, in the case that subgame $\Gamma^{E}$ is realized in the second period, it is socially optimal to induce the entrant's technology in the second period. Specifically, the entrant's good provides a total surplus of $q_{2}+q_{1}+2 b$.

Given the optimal choices of the central planner in the second period in terms of adoption, now we are able to calculate the socially optimal investment behavior. This is calculated in the next subsection.

\subsection{First Period Investment Decisions}

The central planner's objective function considered in the first period, given the optimal choice that is going to be observed in the second period once the innovation process is realized, is given by,

$$
\begin{aligned}
\max _{s_{I}, s_{E}} & s_{I} s_{E}\left(q_{2}+q_{1}+4 b\right)+s_{I}\left(1-s_{E}\right)\left(q_{2}+q_{1}+4 b\right) \\
& +\left(1-s_{I}\right) s_{E}\left(q_{2}+q_{1}+2 b\right)+\left(1-s_{I}\right)\left(1-s_{E}\right)\left(2 q_{1}+4 b\right) \\
& -k s_{I}^{2} / 2-k s_{E}^{2} / 2
\end{aligned}
$$

In order to express the results in a comparable way with respect to the analysis presented for the market outcome, it can be shown that adding and subtracting $q_{1}$, the 
problem of the social planner can be written as,

$$
\begin{aligned}
\max _{s_{I}, s_{E}} & s_{I} s_{E}\left(4 b+q_{\Delta}\right)+s_{I}\left(1-s_{E}\right)\left(4 b+q_{\Delta}\right) \\
& +\left(1-s_{I}\right) s_{E}\left(2 b+q_{\Delta}\right)+4 b\left(1-s_{I}\right)\left(1-s_{E}\right) \\
& +2 q_{1}-k s_{I}^{2} / 2-k s_{E}^{2} / 2
\end{aligned}
$$

In consequence, the first-order conditions are given by,

$$
q_{\Delta}-s_{E}\left(q_{\Delta}-2 b\right)-k s_{I}^{S O}=0
$$

for the incumbent technology, and,

$$
\left(1-s_{I}\right)\left(q_{\Delta}-2 b\right)-k s_{E}^{S O}=0
$$

for the entrant technology.

As in the case for the market outcome, whenever the probabilities $s_{I}$ and $s_{E}$ are in the interval $(0,1)$, the second-order conditions are always less than zero. Therefore, we can find the social optimal levels by solving simultaneously equations $(8)$ and $(9)$ for the values of $s_{I}^{S O}$ and $s_{E}^{S O}$. That is, the social optimal investment levels are given by,

$$
\begin{gathered}
s_{I}^{S O}=1-\frac{k\left(q_{\Delta}-k\right)}{\left(q_{\Delta}+k-2 b\right)\left(q_{\Delta}-k-2 b\right)} \\
s_{E}^{S O}=\frac{\left(q_{\Delta}-2 b\right)\left(q_{\Delta}-k\right)}{\left(q_{\Delta}+k-2 b\right)\left(q_{\Delta}-k-2 b\right)}
\end{gathered}
$$

We can show the following results.

Proposition 5. Without network externalities $(b=0)$ the social optimum and the market outcome are identical

Proof. Comparing equations (5) and (6) for the market outcome and equations (10) and (11) for the social optimum, it can be seen that for $b=0$ there is no inefficiency for any of the firms. 
The result in proposition 5 permits us to isolate the impact of network externalities in the inefficiencies that may arise in the incentives to innovate for both firms.

In addition, by comparing the optimal levels of innovation with the levels achieved privately, we can state the following result.

Proposition 6. In comparison with the social optimum,

i. The incumbent exhibits a too low level of investment.

ii. The entrant exhibits a too high level of investment.

Proof. It follows from comparing equations (5) and (6) for the market outcome and equations $(10)$ and (11) for the social optimum for cases where $b>0$.

This result states that even though the incumbent has increased incentives to innovate given the presence of network externalities, those greater incentives are insufficient from a welfare perspective. The reason for this results comes from the fact that in the market outcome, the private incentives of the incumbent do not consider the potential loss that the first consumer can incur given that is locked-in. This result is presented in Figure 4.

For the case of the entrant, this result implies that, given that he can capture the market (i.e. make profits) only if he is the unique innovator, he would over-invest in R\&D. In this way, the entrant firm maximizes the probability of successful innovation in a socially inefficient way (i.e. rent dissipation). As stated in the introduction, Kristiansen (1996) presents the opposite result. That is, a potential entrant under-invests in R\&D because he opts for a too certain R\&D project, maximizing the probability of successful innovation. Therefore, even though the intuition in both cases is similar, the implications for $R \& D$ expenditures are the exact opposite and arise from the modeling strategy. We believe that in Kristiansen (1996), the assumed mean-preserving spread criterion, although it allows an analysis of $R \& D$ risk, it leads to a unrealistic prediction. In network industries entrants usually tend to heavily (over) invest in R\&D in order to introduce new network incompatible technologies (e.g. interactive TV, Compact Disk (CD), Digital Versatile Disk (DVD), and digital imaging).7

\footnotetext{
${ }^{7}$ Choi (1994) also presents a model where a potential entrant chooses a too certain R\&D project in order to maximize the expected network size. However, Choi (1994) does not consider the implications for $R \& D$ expenditures that are the focus of the present paper.
} 


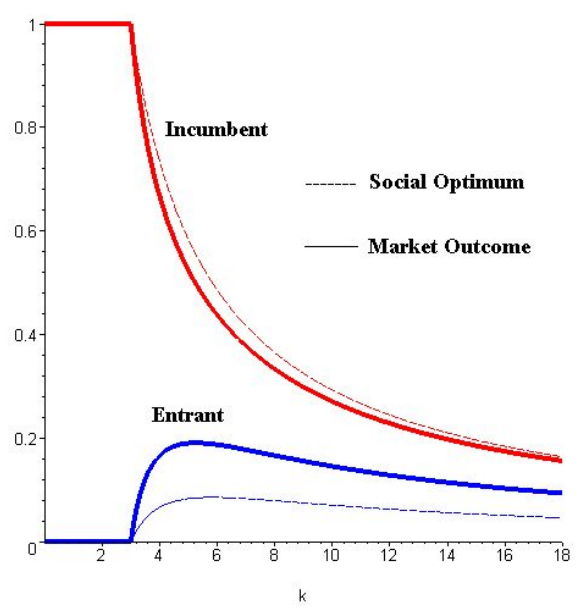

Figure 4: Social Optimum - Investment Levels

The main implication of the results regarding the social efficiency of the market outcome is that, in equilibrium, the new incompatible technology (i.e. the entrant's network good) tend to be adopted too often. Kristiansen (1996) presents the same result. In his paper, entry occurs too often because the entrant chooses a too certain R\&D project, implying a high rate of success and a too low level of investments. In the present model, entry occurs too often because the entrant invests too much in R\&D and captures the market too frequently. Therefore, even though his market outcome results differ from the ones presented here (i.e. he predicts an entrant's inefficient under-investment level), the consequences for social welfare are similar.

These results highlight the importance of an empirical analysis aimed at disentangle the true mechanism behind R\&D incentives and the pattern of adoption of network goods. This is particularly relevant for the design of public policy. For instance, public policies that increase the incentives to innovate for entrant firms (i.e. tax exemptions, R\&D subsidies, patents' design, etc.) will imply opposite effects for social welfare. In Kristiansen (1996), such policies will be welfare-enhancing because they will allow an entrant firm to choose a riskier project, invest more and reduce the inefficiently high entry rate. In the present setup, such policies will be welfare-reducing because they will increase the loss due to the rent dissipation in the $R \& D$ competition stage and will exacerbate the already too high rate of entry. 


\section{Compatibility}

The last two sections dealt with the case when the two firms produce incompatible network goods. However, a common observation is the growing number of alliances in informationtechnology industries in order to attempt to determine common design features in emerging markets. Sometimes the alliances take the form of compatibility agreements (e.g. sharing technologies) in order to maximize network effects.

For instance, a consortium of electronics and computing companies working on DVD development are attempting to agree on common standards to try to avoid the VHS/Beta standards battle. IBM decided to open its PC architecture and Nokia announced that it would share its mobile technology with other firms.

At the same time, in some recent cases like the video game industry and the introduction of digital TV, it has been clear that competition takes place with incompatible standards. Moreover, there is no clear answer under which conditions industry competition favors compatibility or incompatibility. For instance, Phillips and Sony agreed on a Compact Disk (CD) standard but are now entering a contest to determine the new digital audio format 8

This section provides an illustration of the role of compatibility in a network market and its impact on the incentives to perform $R \& D$ investments. In the setup presented in this paper, full compatibility implies that each group of consumers benefit from the total network effects. That is, additional to the stand-alone value of the network good, the value of the network benefits is common to all consumers and equal to $4 b$. Therefore, in the price competition stage the network benefits provide no advantage to any firm and the first period R\&D market equilibrium is identical to the case without network effects with optimal investments in R\&D symmetric and equal to $q_{\Delta} /\left(q_{\Delta}+k\right)$ (i.e. a price-quality competition determined by a $\mathrm{R} \& \mathrm{D}$ race).$^{9}$

However, what makes the present analysis different to a regular R\&D race under quality differentiation is the impact on consumer surplus. That is, the network benefits

\footnotetext{
${ }^{8}$ See Reilly (1993) and Besen and Farrell (1994).

${ }^{9}$ Under compatibility, the firms' problem is defined by $\max _{s_{i}} s_{i}\left(1-s_{j}\right)\left(q_{\Delta}\right)-k s_{i}^{2} / 2$ where $i, j \in\{I, E\}$ and $i \neq j$. The social planner problem is equal to $\max _{s_{I}, s_{E}} s_{I} s_{E}\left(q_{\Delta}\right)+s_{I}\left(1-s_{E}\right)\left(q_{\Delta}\right)+\left(1-s_{I}\right) s_{E}\left(q_{\Delta}\right)+$ $\left(1-s_{I}\right)\left(1-s_{E}\right)+4 b+2 q_{1}-k s_{I}^{2} / 2-k s_{E}^{2} / 2$.
} 


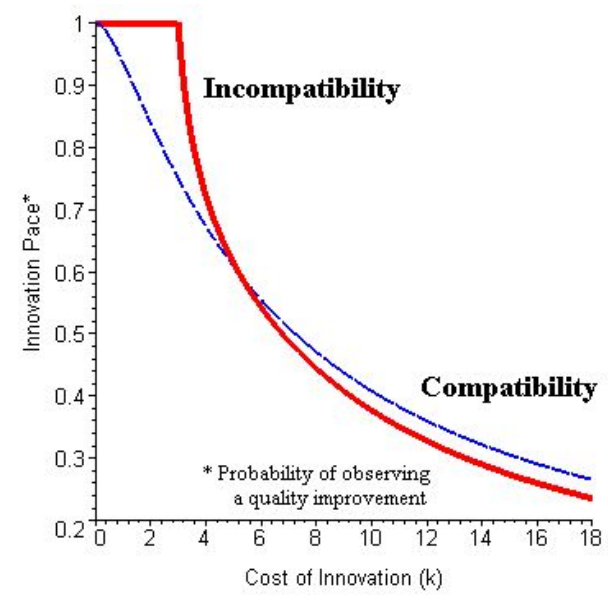

Figure 5: Innovation Pace

do not affect the outcome of firms' competition and the social planner but do influence the final surplus enjoyed by consumers. By solving the problem under compatibility it can be shown that even though industry profits are always higher under incompatibility, a social planner would always impose a compatibility agreement.

Moreover, under compatibility, private $R \& D$ incentives are not only symmetric but efficient. This result is not surprising because compatibility implies that the network benefits are common to all groups of consumers, and this fact is known by private firms, as well as by the social planner.

However, note that this compatibility-led efficiency implies that the incumbent firm invests less and the entrant invests more than the levels that would be observed under incompatibility. Therefore, as the net effect depends on parameters' values, compatibility does not necessarily reduces the intensity of the $R \& D$ competition as has been suggested for example by Katz and Ordover (1990) and Kristiansen (1998). In consequence, it can be stated that compatibility per se does not reduce the pace of innovation in a network industry.10

The reason for this is the presence of endogenous and uncertain quality differentiation. In Kristiansen (1998) the only source of differentiation (in expectations) between the incumbent and the potential entrant is the presence of an installed base. Therefore,

\footnotetext{
${ }^{10}$ In the 70's, the US National Bureau of Standards refused to write interface standards for the computer industry claiming that standards would retard innovation. See Hemenway (1975).
} 
compatibility eliminates all possible sources of advantages for the competing firms, while in our case differentiation can still be achieved through successful R\&D initiatives ${ }^{11}$

In our model, it can be shown that for high costs of innovation, compatibility actually increases the R\&D competition intensity, evidencing a higher pace of innovation. Defining the pace of innovation as the probability of observing a quality improvement in any of the offered goods (i.e. $1-x$ where $x$ is the probability that no firm innovates), Figure 5 shows this result.

\section{Conclusions}

In the present paper, we have presented a simplified two-period duopoly model of competition with uncertain technological progress in order to determine the private incentives to innovate and its relation with the social incentives.

We have presented four main results. First, for low cost of innovation entry does not occur at all and for high cost of innovating, entry occurs with positive probability. This result highlights the preemptive power of the innovation incentives. That is, for low cost of innovation the incumbent firm may increase enough the probability of achieving the innovation, eliminating the entrant's incentives to attempt to capture the market.

Second, when entry is possible, the incumbent invests always more than the entrant and, therefore, there is a high probability that the incumbent maintains its monopoly position. This result implies, that even though the incumbent has an advantage to keep monopolizing the market, he is forced to innovate given the threat of entry.

Third, from a welfare perspective, the incumbent invests too little and the entrant invests too much given the existence of locked-in consumers. That is, neither the incumbent firm nor the entrant takes into account the impact on welfare of the first period consumers and this generates the social suboptimal outcome. These efficiency results are solely due to the presence of network externalities.

Finally, fourth, by choosing to produce compatible products, firms do not necessarily reduce the $\mathrm{R} \& \mathrm{D}$ competition intensity as has been argued for example in Katz and Or-

\footnotetext{
${ }^{11}$ Farrell and Katz (1998) also argue that R\&D competition with uncertain outcomes tends to create winners and losers. Winners prefer incompatibility.
} 
dover (1990) and Kristiansen (1998). This is due to the presence of endogenous quality differentiation. Moreover, compatibility is always preferred from a social welfare perspective and for high cost of innovation it may even increase the pace of innovation observed in the industry.

It should be recognized that the model might, and should, be extended to a fully dynamic setting and must consider a richer set of options for the involved firms. In addition, comparisons with case studies or empirical regularities might enrich the results. 


\section{References}

Arthur, W.B., (2000), "Myths and Realities of the High-Tech Economy", Talk given at Credit Suisse First Boston Though Leader Forum, Santa Fe Institute.

Choi, J.P., (1994), "Irreversible Choice of Uncertain Technologies with Network Externalities", Rand Journal of Economics, 25, 382-401.

Besen, S. and J. Farrell, (1994), "Choosing How to Compete: Strategies and Tactics in Standardization", Journal of Economic Perspectives, 8, 117-131.

De Bijil, P.W.J. and S. Goyal, (1995), "Technological Change in Markets with Network Externalities", International of Industrial Organization, 13, 307-325.

Dasgupta, P. and E. Maskin, (1987), "The Simple Economics of Research Portfolios", The Economic Journal, 97, 581-595.

Farrell, J. and M. Katz, (1998), "The Effects of Antitrust and Intellectual Property Law on Compatibility and Innovation", Antitrust Bulletin, 609-650.

Farrell, J. and M. Katz, (2005), "Competition or Predation? Consumer Coordination, Strategic Pricing and Price Floors in Network Markets", Journal of Industrial Economics, LIII, 203-231.

Farrell, J. and G. Saloner, (1985), "Standardization, Compatibility and Innovation", Rand Journal of Economics, 16, 70-83.

Farrell, J. and G. Saloner, (1986), "Installed Base and Compatibility: Innovation, Product Preannouncement, and Predation", American Economic Review, 76, 940-955.

Fudenberg, D. and J. Tirole, (2000), "Pricing a Network Good to Deter Entry", Journal of Industrial Economics, XLVIII, 373-390.

Hemenway, D., (1975), "Industrywide Voluntarily Product Standards". Cambridge, Mass: Ballinger Pub. Co. 
Katz, M. and C. Shapiro, (1985), "Network Externalities, Competition and Compatibility", American Economic Review, 75, 424-440.

Katz, M. and C. Shapiro, (1986), "Technology Adoption in the Presence of Network Externalities", Journal of Political Economy, 94, 822-884

Katz, M. and C. Shapiro, (1992), "Product Introduction with Network Externalities", Journal of Industrial Economics, 40, 55-84

Katz, M. and C. Shapiro, (1994), "Systems Competition and Network Effects", Journal of Economic Perspectives, 8, 93-115.

Katz, M. and J. Ordover, (1990), "R\&D Cooperation and Competition", Brookings Papers on Economic Activity, Special Issue, 137-191.

Kristiansen, E.G., (1996), "R\&D in Markets with Network Externalities", International Journal of Industrial Organization, 14, 769-784.

Kristiansen, E.G., (1998), "R\&D in the Presence of Network Externalities: Timing and Compatibility", Rand Journal of Economics, 29, 531-547.

Reilly, P.M., (1993), "Sony's Digital Audio Format Pulls Ahead of Phillip's but Both Have Still Far to Go", The Wall Street Journal, August 6, pp. B1-2.

Reinganum, J., (1989), "The Timing of Innovation: Research, development and diffusion". In R. Schmalensee and R. Willig, (eds.) (1989). Handbook of Industrial Organization, North-Holland. 849-908.

Shapiro, C. and H. Varian, (1999). Information Rules: A strategic guide to the network economy. Harvard Business School Press. 